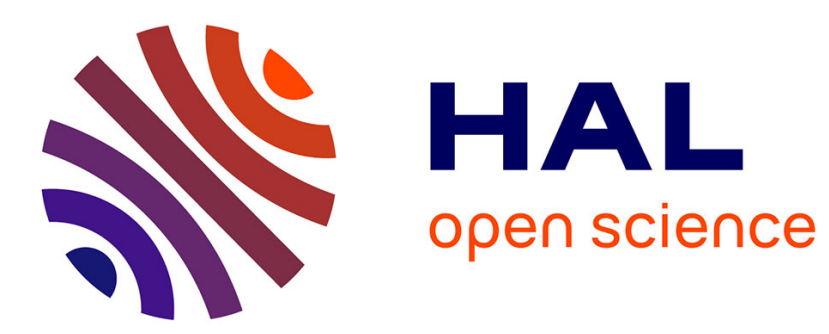

\title{
Experimental evidence for the strong interpenetration of two polymer chains very different in size
}

\author{
A. Lapp, M. Mottin, C. Strazielle, Daniel Broseta, L. Leibler
}

\section{To cite this version:}

A. Lapp, M. Mottin, C. Strazielle, Daniel Broseta, L. Leibler. Experimental evidence for the strong interpenetration of two polymer chains very different in size. Journal de Physique II, 1992, 2 (5), pp.1247-1256. 10.1051/jp2:1992197 . jpa-00247711

\section{HAL Id: jpa-00247711 https://hal.science/jpa-00247711}

Submitted on 1 Jan 1992

HAL is a multi-disciplinary open access archive for the deposit and dissemination of scientific research documents, whether they are published or not. The documents may come from teaching and research institutions in France or abroad, or from public or private research centers.
L'archive ouverte pluridisciplinaire HAL, est destinée au dépôt et à la diffusion de documents scientifiques de niveau recherche, publiés ou non, émanant des établissements d'enseignement et de recherche français ou étrangers, des laboratoires publics ou privés. 


\title{
Experimental evidence for the strong interpenetration of two polymer chains very different in size
}

\author{
A. Lapp $\left({ }^{1}\right)$, M. Mottin $\left({ }^{2}\right)$, C. Strazielle $\left({ }^{2}\right)$, D. Broseta $\left({ }^{3}\right)$ and L. Leibler $\left({ }^{3}\right)$ \\ (1) Laboratoire Léon Brillouin (CEA-CNRS), CEN de Saclay, 91191 Gif sur Yvette Cedex, \\ France \\ (2) Institut Charles Sadron (CRM-EAHP) (CNRS-ULP), 6 rue Boussingault, 67083 Strasbourg \\ Cedex, France \\ (3) Laboratoire de Physico-Chimie Théorique, ESPCI, 75231 Paris Cedex 05, France
}

(Received 1 July 1991, revised 14 November 1991, accepted 7 January 1992)

\begin{abstract}
Résumé. - La fonction d'interpénétration de différents mélanges de polymères, en bons solvants, de même nature chimique, mais de longueurs différentes, a été déterminée au moyen de la diffusion de la lumière. Les résultats obtenus ont été comparés à deux modèles théoriques. L'un considère les polymères comme des sphères dures non interpénétrées, l'autre introduit un modèle de «blob » fortement interpénétré. Les résultats expérimentaux montrent un bon accord avec cette seconde théorie.
\end{abstract}

\begin{abstract}
The interpenetration function of some polymer mixture solutions in a good solvent is examined in the case of polymers of the same chemical species but with very different sizes. The results are compared to two theoretical models. In the first one, the polymers are considered as non-interpenetrating hard-spheres and, in the second one, a blob model of strongly interpenetrated chains is introduced. The experimental results show a better agreement with the second theory.
\end{abstract}

\section{Introduction.}

Excluded volume effects are extremely important in dilute polymer solutions in a good solvent $[1,2]$. The aim of this paper is to examine the influence of the chain length distribution on the scattering properties of such solutions. Up to now, the interpenetration problem has been investigated essentially with mixtures of polystyrene [3,4] or poly- $\alpha$-methylstyrene [5] and the results interpreted by various two-parameter perturbation theories assuming that polymer coils behave like hard spheres Recent theoretical studies have been devoted to this problem [6-8] and renormalisation group analysis shows that chains of different sizes interpenetrate each other more srongly than the classical « hard-sphere » model predicts [7, 8]. Deviation to the hard-sphere model have already been observed by some experimentalists [3-5] and their interpretation consists in saying that effectively the polymer of lower molecular weight may penetrate into the other polymer coil $[3,4]$. This effect is examined here for the 
case of several mixtures of polymer with very different sizes : mixtures of poly-metylmethacrylate, poly-dimethylsiloxane and polystyrene. The experimental results are compared with two models. In the first one, we consider the polymers as non interpenetrating hard-spheres (HS) and in the second, a blob picture (B) is introduced to take into account the interpenetration of the chains.

\section{Description of the models.}

Long polymer chains dissolved in a good solvent repel each other because of excluded volume interactions between monomers. In dilute solutions, the interactions between polymer molecules are characterized by the second virial coefficient $A_{2}$ which can be obtained from osmotic pressure or light scattering by the following relations :

$$
\begin{aligned}
\frac{\Pi}{c R T} & =\frac{1}{M_{\mathrm{n}}}+A_{2} c+\cdot \\
\frac{K c}{I_{0}} & =\frac{1}{R T} \frac{\delta \Pi}{\delta c}=\frac{1}{M_{\mathrm{w}}}+2 A_{2} c+\cdot
\end{aligned}
$$

where $\Pi$ is the osmotic pressure, $I_{0}$ the scattering intensity at zero scattering angle, $K$ an optical constant, $M_{\mathrm{n}}$ and $M_{\mathrm{w}}$ are number and weight average molecular weights respectively, $c$ the ponderal concentration of polymer and $R T$ the absolute temperature in energy units. In good solvent, these interactions are repulsive and prevent two chains of equal sizes from interpenetrating mutually : the polymers behave like hard spheres. Namely, the dimensionless second virial coefficient, or interpenetration function, between two chains $i$ [9] :

$$
\Psi_{u}=\frac{A_{2, i i} M_{i}^{2}}{4 \pi^{3 / 2} R_{\mathrm{G}, i}^{3} \mathcal{N}_{\mathrm{A}}}
$$

is a universal numerical constant $\Psi^{*}$ in the asymptotic limit of infinite chains $[7,10,11](M$ and $R_{\mathrm{G}}$ are the molecular weight and the radius of gyration of the chains and $\mathcal{N}_{\mathrm{A}}$ the Avogadro number). With this definition, the interpenetration function appears, in a natural way, in the expansion of the osmotic pressure $\Pi$ as a function of concentration $c$ :

$$
\frac{\Pi M}{c R T}=1+3 \pi^{1 / 2} \Psi \frac{c}{c^{*}}
$$

or in a similar way for the scattering intensity :

$$
\frac{K c M}{I_{0}}=1+6 \pi^{1 / 2} \Psi \frac{c}{c^{*}}
$$

where $c^{*}$ is the overlap concentration :

$$
c^{*}=\frac{M}{(4 / 3) \pi R_{\mathrm{G}}^{3} \mathcal{N}_{\mathrm{A}}}
$$

This constant has been experimentally measured, after correction of polydispersity by using a Schulz distribution. Its meaning value [12], $\Psi=0.24 \pm 0.04$, is in agreement with several renormalization group calculations $[7,10,11]$.

The hard-sphere picture, in which the polymer chain may be viewed as a cloud of monomers with uniform density, is somewhat misleading, because it does not take into account the fractal nature of polymer conformations. Two polymer chains, even in a good 
solvent, may interpenetrate in fact very strongly $[8,13]$. This is best shown by studying the interactions between two chains of different sizes [8].

Indeed when the sizes of the chains are not very different, the hard sphere picture [14] should remain a valid approximation (see Fig. 1). The mutual interpenetration function

$$
\Psi_{\mathrm{LS}}=\frac{A_{2, \mathrm{LS}} M_{\mathrm{S}} M_{\mathrm{L}}}{4 \pi^{3 / 2}\left(\frac{R_{\mathrm{G}, \mathrm{L}}+R_{\mathrm{G}, \mathrm{S}}}{2}\right)^{3} \mathcal{N}_{\mathrm{A}}}
$$

where $A_{2, L S}$ is the mutual second virial coefficient between small (S) and long (L) chains, should thus stay close to its monodisperse value $\Psi=0.24$.

However, when the chains are very different in sizes, one expects the small chain to fully penetrate the large chain (see Fig. 1) [8]. The interactions may be understood within the «blob» picture represented in figure $1:$ the mutual excluded volume $\zeta_{L S}$ is equal to the volume of the small chain multiplied by the number of times the small chain may be replicated in the larger one, i.e. $M_{\mathrm{L}} / M_{\mathrm{S}}$ times,

$$
\zeta_{\mathrm{LS}}=A_{2, \mathrm{LS}} M_{\mathrm{S}} M_{\mathrm{L}}=4 \pi^{3 / 2} \Psi_{\mathrm{LS}} R_{\mathrm{G}, \mathrm{S}}^{3} \frac{M_{\mathrm{L}}}{M_{\mathrm{S}}} \mathcal{N}_{\mathrm{A}}
$$

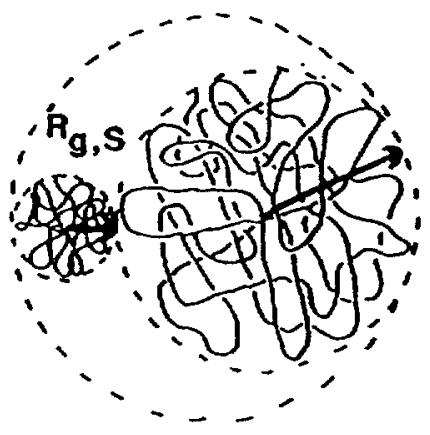

a)

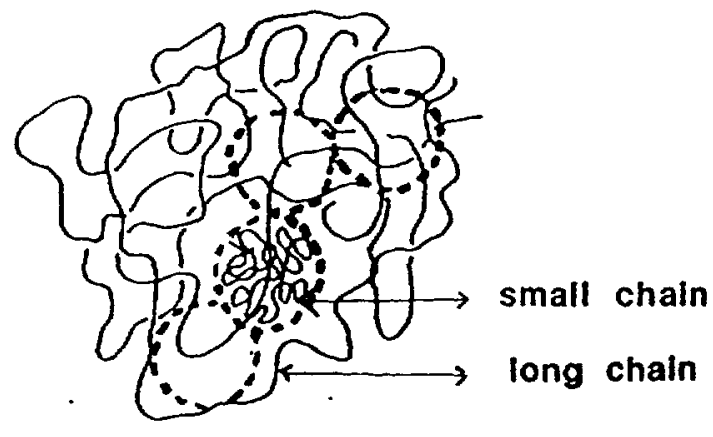

b)

Fig. 1. - Hard sphere versus Blob pictures. In the hard sphere pictures (a) the excluded volume is $\left(R_{\mathrm{G}, \mathrm{S}}+R_{\mathrm{G}, \mathrm{L}}\right)^{3}$, whereas in the blob picture (b) it is $R_{\mathrm{G}, \mathrm{S}}^{3} M_{\mathrm{L}} / M_{\mathrm{S}}$.

$\Psi_{\text {LS }}$ has been calculated by R. G. techniques $[6,8]$ and found to be slightly inferior to $\Psi$ :

$$
\frac{\Psi_{\mathrm{LS}}}{\Psi_{\mathrm{SS}}}=1-\frac{\varepsilon}{8}(-1+4 \operatorname{Ln} 2) \approx 0.78
$$

with

$$
\Psi_{\mathrm{SS}}=\frac{A_{2, \mathrm{ss}} M_{\mathrm{S}}^{2}}{4 \pi^{3 / 2} R_{\mathrm{G}, \mathrm{S}}^{3} \mathcal{N}_{\mathrm{A}}}
$$

and

$$
\Psi_{\mathrm{LS}}=\frac{A_{2, \mathrm{LS}} M_{\mathrm{S}} M_{\mathrm{L}}}{4 \pi^{3 / 2} R_{\mathrm{G}, \mathrm{S}}^{3} \frac{M_{\mathrm{L}}}{M_{\mathrm{S}}} \mathcal{N}_{\mathrm{A}}}=\frac{A_{2, \mathrm{LS}} M_{\mathrm{S}}^{2}}{4 \pi^{3 / 2} R_{\mathrm{G}, \mathrm{S}}^{3} \mathcal{N}_{\mathrm{A}}}
$$


the corresponding interpenetration functions and where, in the d-dimensional space, $\varepsilon=4-d$, so that the mutual second virial coefficient $A_{2, \text { LS }}$ is very close to the second virial coefficient of the smallest chain :

$$
A_{2, \mathrm{SS}}>A_{2, \mathrm{LS}}^{\mathrm{B}}>A_{2, \mathrm{LL}} \text {. }
$$

In contrast, the mutual second coefficient of two hard-spheres, according to the Cassassa theory, is much larger than the second virial coefficient of the smallest sphere. Namely the ratio of the excluded volumes, for $R_{\mathrm{G}, \mathrm{L}} \gg R_{\mathrm{G}, \mathrm{S}}$, is :

$$
\frac{\zeta_{\mathrm{LS}}}{\zeta_{\mathrm{SS}}}=\frac{M_{\mathrm{S}} M_{\mathrm{L}} A_{2, \mathrm{LS}}^{\mathrm{HS}}}{M_{\mathrm{S}}^{2} A_{2, \mathrm{SS}}}=\left(\frac{R_{\mathrm{G}, \mathrm{S}}+R_{\mathrm{G}, \mathrm{L}}}{R_{\mathrm{G}, \mathrm{S}}}\right)^{3} \approx\left(\frac{R_{\mathrm{G}, \mathrm{L}}}{R_{\mathrm{G}, \mathrm{s}}}\right)^{3} \approx\left(\frac{M_{\mathrm{L}}}{M_{\mathrm{S}}}\right)^{3 \nu}
$$

where $\nu \approx 3 / 5$ is the excluded volume exponent. For polymer chains with very different sizes, we thus have, in the hard sphere (smoothed density) approximation, the opposite inequality

$$
A_{2, \mathrm{LS}}^{\mathrm{HS}}>A_{2, \mathrm{SS}}>A_{2, \mathrm{LL}} \text {. }
$$

In the aim of assessing the validity of these two — « hard-sphere » and «blob» - models, we have studied by light scattering several polymers - polymer - solvent systems in which the ratio of the molecular weights of the two polymer homologues $r=R_{\mathrm{G}, \mathrm{L}} / R_{\mathrm{G}, \mathrm{s}}$ is large.

\section{Experimental part.}

The measurements were performed on four systems containing two polymers of the same chemical nature but with large size differences (long molecule + small molecule) : two systems with polystyrene (PS) in toluene, one of polymethylmethacrylate (PMMA) in tetrahydrofurane and one with polydimethylsiloxane (PDMS) in toluene. The solvents are good solvents for every polymer. PS samples were prepared by anionic polymerisation following the classical procedure, PMMA and PDMS samples are fractions from polymers obtained by radical and cationic polymerisation respectively.

The molecular characteristics (weight average molecular weight $M_{\mathrm{W}}$, radius of gyration $R_{\mathrm{G}}$ and second virial coefficient $A_{2}$ of the samples are summarized in table I. They have been determined by light scattering. The polydispersity $M_{\mathrm{w}} / M_{\mathrm{n}}$ was evaluated by size exclusion chromatography (SEC), generally, the index of polydispersity is smaller than 1.2 for small molecules and higher (from 1.35 to 2.10) for long molecules. Table I also shows the same parameters of the mixtures studied by Sato et al. [3] and Noda et al. [5].

The mixtures were made in weight fraction and the solutions were clarified by centrifugation at $15000 \mathrm{rpm}$ during $2 \mathrm{~h}$. The light scattering measurements were performed at $25^{\circ} \mathrm{C}$ with a FICA 50 apparatus in vertically polarized incident beam at $\lambda=546 \mathrm{~nm}$ and sometimes at $632 \mathrm{~nm}$ (on a Fica 42000 modified). The data were analysed in terms of Zimm plot. The accuracy of the results is about $5 \%$ for the molecular weight and the radius of gyration and 5 to $10 \%$ for the second virial coefficient.

In figure 2, we have reported the results for the system 4 (mixture of PDMS in toluene). The weight average molecular weight presents, as expected, a linear variation with the weight fraction of the long molecule $w_{L}$, whereas the second virial coefficient decreases rapidly in the range of small proportions of long molecules. The same behaviour is observed for the other systems. 
Table I. - Molecular characteristics of polymers used: weight average molecular weight $M_{\mathrm{W}}$, second virial coefficient $A_{2}$, radius of gyration $R_{\mathrm{G}}$, interpenetration fonction $\Psi$, and polydispersity $M_{\mathrm{W}} / M_{\mathrm{N}}\left(M_{\mathrm{N}}\right.$. number average molecular weight). (a) Reference [3] (Sato et al.); (b) reference [5] (Noda et al.).

\begin{tabular}{|c|c|c|c|c|c|c|c|}
\hline Mixture & Polymer & Solvent & $M_{\mathrm{W}} \times 10^{-6}$ & $\underset{\AA}{R_{\mathrm{G}}}$ & $\mid \begin{array}{c}A_{2} \times 10^{4} \\
\text { mol.ml.g }\end{array}$ & $\Psi$ & $M_{\mathrm{W}} / M_{\mathrm{N}}$ \\
\hline \multirow[t]{2}{*}{1} & \multirow[t]{2}{*}{ PS } & \multirow[t]{2}{*}{ Toluene } & 2.950 & 1052 & 2.52 & 0.140 & 1.45 \\
\hline & & & 0.118 & 128 & 5.14 & 0.263 & 1.05 \\
\hline \multirow[t]{2}{*}{2} & \multirow[t]{2}{*}{ PS } & \multirow[t]{2}{*}{ Toluene } & 2.600 & 1424 & 1.84 & 0.032 & 2.10 \\
\hline & & & 0.270 & 210 & 4.80 & 0.282 & 1.02 \\
\hline \multirow[t]{2}{*}{3} & \multirow[t]{2}{*}{ PDMS } & \multirow[t]{2}{*}{ Toluene } & 1.220 & 541 & 2.68 & 0.188 & 1.32 \\
\hline & & & 0.134 & 159 & 4.18 & 0.131 & 1.16 \\
\hline \multirow[t]{2}{*}{4} & \multirow[t]{2}{*}{ PMMA } & \multirow[t]{2}{*}{ THF } & 1.030 & 470 & 2.44 & 0.186 & 1.40 \\
\hline & & & 0.180 & 142 & 4.12 & 0.348 & 1.15 \\
\hline \multirow[t]{2}{*}{5} & \multirow[t]{2}{*}{ PS (a) } & \multirow[t]{2}{*}{ Benzene } & 4.380 & 1040 & 2.05 & 0.261 & 1.04 \\
\hline & & & 0.0447 & (71) & 7.40 & 0.341 & 1.01 \\
\hline \multirow[t]{2}{*}{6} & \multirow[t]{2}{*}{ PS (a) } & \multirow[t]{2}{*}{ Benzene } & 4.380 & 1040 & 2.05 & 0.261 & 1.04 \\
\hline & & & 0.379 & 240 & 4.10 & 0.318 & 1.02 \\
\hline \multirow[t]{2}{*}{7} & \multirow[t]{2}{*}{$\mathrm{P} \alpha \mathrm{MS}$ (b) } & \multirow[t]{2}{*}{ Toluene } & 1.230 & 480 & 1.75 & 0.179 & 一 \\
\hline & & & 0.210 & 178 & 2.91 & 0.176 & - \\
\hline
\end{tabular}

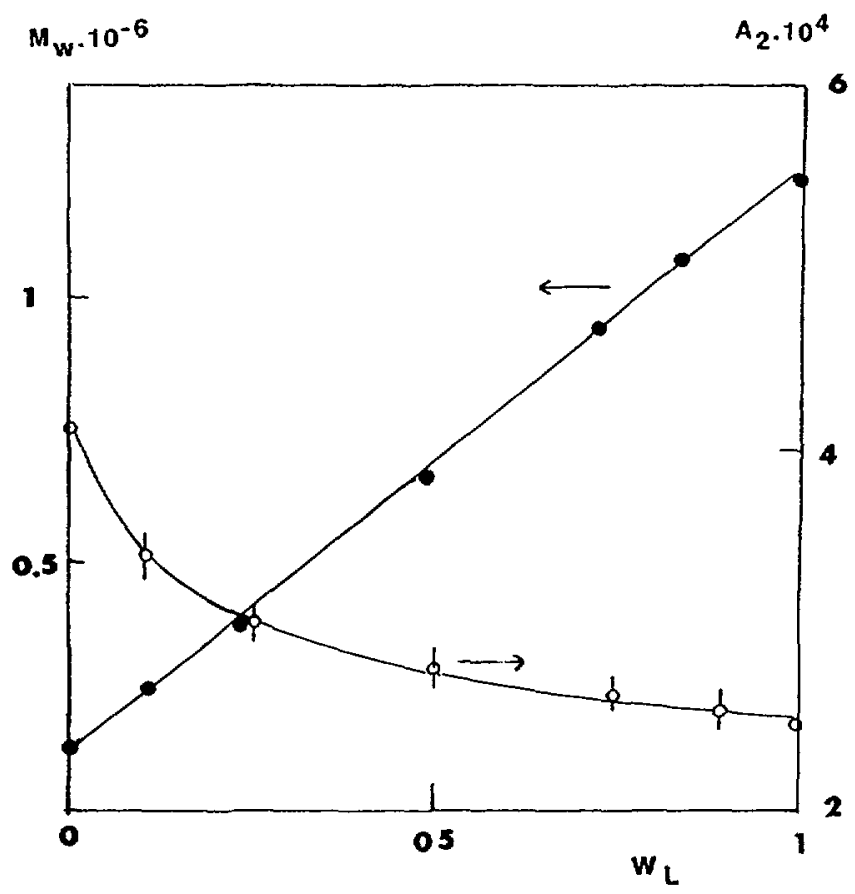

Fig. 2. - Light scattering data for the mixture 4 (PDMS in toluene) : variation of molecular weight $M_{\mathrm{W}}$ and second virial coefficient $A_{2}$ versus the weight fraction $W_{\mathrm{L}}$. 


\section{Results and comments.}

For a multi-component polymer solution, the light-scattering second virial coefficient is given, according to the fluctuation-dissipation theory $[15,16]$, by the following relation :

$$
A_{2}=\frac{\sum_{\imath, j=1}^{N} A_{\imath \jmath} M_{\imath} M_{j} W_{i} W_{J}}{\left(\sum_{\imath}^{N} M_{\imath} W_{\imath}\right)^{2}}=\sum_{\imath, j=1}^{N} \frac{A_{i j} M_{i} M_{J} W_{\imath} W_{J}}{M_{\mathrm{W}}^{2}}
$$

where $W_{1}$ (or $W_{j}$ ) is the weight fraction of polymer $i$ (or $j$ ) in the solute $\left(W_{t}+W_{j}=1\right.$ ). Here for the mixture of long and short chains (bimodal distribution) in a solvent, one obtains a combination of the three coefficients $A_{2, \mathrm{sS}}, A_{2, \mathrm{LL}}, A_{2, \mathrm{LS}}$.

$$
A_{2}=A_{2, \mathrm{LL}} \Phi_{\mathrm{L}}^{2}+2 A_{2, \mathrm{LS}} \Phi_{\mathrm{L}} \Phi_{\mathrm{S}}+A_{2, \mathrm{ss}} \Phi_{\mathrm{S}}^{2}
$$

with

$$
\Phi_{i}=\frac{c_{1} M_{\mathrm{W}, i}}{c_{\mathrm{L}} M_{\mathrm{W}, \mathrm{L}}+c_{\mathrm{S}} M_{\mathrm{W}, \mathrm{S}}}=\frac{W_{\imath} M_{\mathrm{W}, t}}{W_{\mathrm{L}} M_{\mathrm{W}, \mathrm{L}}+W_{\mathrm{S}} M_{\mathrm{W}, \mathrm{S}}}
$$

where $c_{l}$ is the concentration of polymer $i$ and $M_{\mathrm{W}, t}$ its molecular weight.

It is interesting to note that, when inequality (8) is verified, according to Casassa [14], the function $A_{2}\left(\Phi_{L}\right)$ has a maximum. On the contrary, there is no maximum when inequality (6) is verified. The presence of a maximum in $A_{2}\left(\Phi_{\mathrm{L}}\right)$ is the signature of a hard sphere behavior.

For each bimodal polymer solution, we have determined the second virial coefficient $A_{2}\left(\Phi_{\mathrm{L}}\right)$ for seven different values of $\Phi_{\mathrm{L}}$ (Tab. II). In figure 3 we have displayed the results corresponding to the system 2 and the theoretical variation of $A_{2}\left(\Phi_{L}\right)$ according to the two models.

- for the «blob» model with equations (4), (5a) and (5b) we have :

$$
A_{2, \mathrm{LS}}=0.78 A_{2, \mathrm{ss}}
$$

- for the «hard-sphere» model with equations (2) and (5a) and assuming that $\psi_{\mathrm{LS}} \approx \psi_{\mathrm{SS}}$.

$$
A_{2, \mathrm{LS}}=\frac{1}{8} A_{2, \mathrm{ss}} \frac{M_{\mathrm{S}}}{M_{\mathrm{L}}}\left(1+\frac{R_{\mathrm{G}, \mathrm{L}}}{R_{\mathrm{G}, \mathrm{s}}}\right)^{3}
$$

We find no evidence for a maximum in $A_{2}\left(\phi_{\mathrm{L}}\right)$. This is in agreement with the results of Sato et al., or Noda et al., who find a very slight maximum for a PS-Benzene system with a ratio $r=4$ and no maximum for a similar system with $r=15$. This indicates that, qualitatively, the interactions between two polymer chains may be seen as hard sphere interactions only when the sizes of the chains are not very different.

In order to determine $A_{2, \text { LS }}$ directly for every mixture, we transform the relation (9) into :

$$
\frac{A_{2}-A_{2, \mathrm{SS}} \Phi_{\mathrm{S}}^{2}}{\Phi_{\mathrm{L}} \boldsymbol{\Phi}_{\mathrm{S}}}=2 A_{2, \mathrm{LS}}+A_{2, \mathrm{LL}} \frac{\Phi_{\mathrm{L}}}{\Phi_{\mathrm{S}}}
$$

This relation allows a determination of $A_{2, L S}$, after extrapolation at $\Phi_{L} / \Phi_{S}=0$, by the last squares method, with a better accuracy than a direct determination using equation (9). The experimental data for the mixtures are given in figure 4 and table III. We have added some 
Table II. - Variations of the molecular parameters as a fonction of the composition for the mixtures 2 (PS-Toluene), 3 (PMMA-THF) and 4 (PDMS-toluene).

\begin{tabular}{|c|c|c|c|c|}
\hline$W_{\mathrm{L}}$ & $\phi_{\mathrm{L}}$ & $M_{\mathrm{W}} \times 10^{-6}$ & $\begin{array}{l}R_{\mathrm{G}} \\
(\AA)\end{array}$ & $\begin{array}{c}A_{2} \times 10^{4} \\
\left(\mathrm{~mol} . \mathrm{ml} . \mathrm{g}^{-2}\right)\end{array}$ \\
\hline \multicolumn{5}{|c|}{ Mixture 2} \\
\hline 1.00 & 1.00 & 2.600 & 1424 & 1.84 \\
\hline 0.72 & 0.96 & 2.100 & 1380 & 2.02 \\
\hline 0.49 & 0.90 & 1.520 & 1307 & 2.63 \\
\hline 0.25 & 0.76 & 0.842 & 1064 & 2.69 \\
\hline 0.15 & 0.63 & 0.634 & 971 & 3.49 \\
\hline 0.10 & 0.52 & 0.492 & 806 & 3.51 \\
\hline 0.00 & 0.00 & 0.270 & 210 & 4.80 \\
\hline \multicolumn{5}{|c|}{ Mixture 3} \\
\hline 1.00 & 1.00 & 1.220 & 541 & 2.68 \\
\hline 0.84 & 0.98 & 1.065 & 557 & 2.42 \\
\hline 0.72 & 0.96 & 0.936 & 555 & 2.70 \\
\hline 0.49 & 0.90 & 0.647 & 489 & 2.49 \\
\hline 0.23 & 0.73 & 0.356 & 401 & 3.00 \\
\hline 0.11 & 0.52 & 0.234 & 335 & 3.70 \\
\hline 0.00 & 0.00 & 0.134 & 159 & 4.18 \\
\hline \multicolumn{5}{|c|}{ Mixture 4} \\
\hline 1.00 & 1.00 & 1.030 & 470 & 2.44 \\
\hline 0.90 & 0.98 & 0.978 & 461 & 2.57 \\
\hline 0.75 & 0.95 & 0.830 & 479 & 2.65 \\
\hline 0.50 & 0.85 & 0.624 & 435 & 2.85 \\
\hline 0.25 & 0.66 & 0.397 & 395 & 3.05 \\
\hline 0.10 & 0.39 & 0.291 & 315 & 3.76 \\
\hline 0.00 & 0.00 & 0.180 & 142 & 4.12 \\
\hline
\end{tabular}

results of Sato et al., and Noda et al. in this table. Thus a more unambiguous test of the theories may be achieved by comparing the values for the mutual interpenetration function calculated :

i) in the hard-sphere approximation (relation (2))

$$
\Psi_{\mathrm{LS}}^{\mathrm{HS}}=\frac{A_{2, \mathrm{LS}} M_{\mathrm{S}} M_{\mathrm{L}}}{4 \pi^{3 / 2}\left(\frac{R_{\mathrm{G}, \mathrm{S}}+R_{\mathrm{G}, \mathrm{L}}}{2}\right)^{3} \mathcal{N}_{\mathrm{A}}}
$$

ii) in the blob model (relation (5b))

$$
\Psi_{\mathrm{LS}}^{\mathrm{B}}=\frac{A_{2, \mathrm{LS}} M_{\mathrm{S}}^{2}}{4 \pi^{3 / 2} R_{\mathrm{G}, \mathrm{S}}^{3} \mathcal{N}_{\mathrm{A}}}
$$

This is done in table III. Clearly, the blob model is in better agreement with a mean value of $0.25 \pm 0.07$ for $\Psi_{\mathrm{LS}}^{\mathrm{B}}$ that cannot however be distinguished from the monodisperse value 


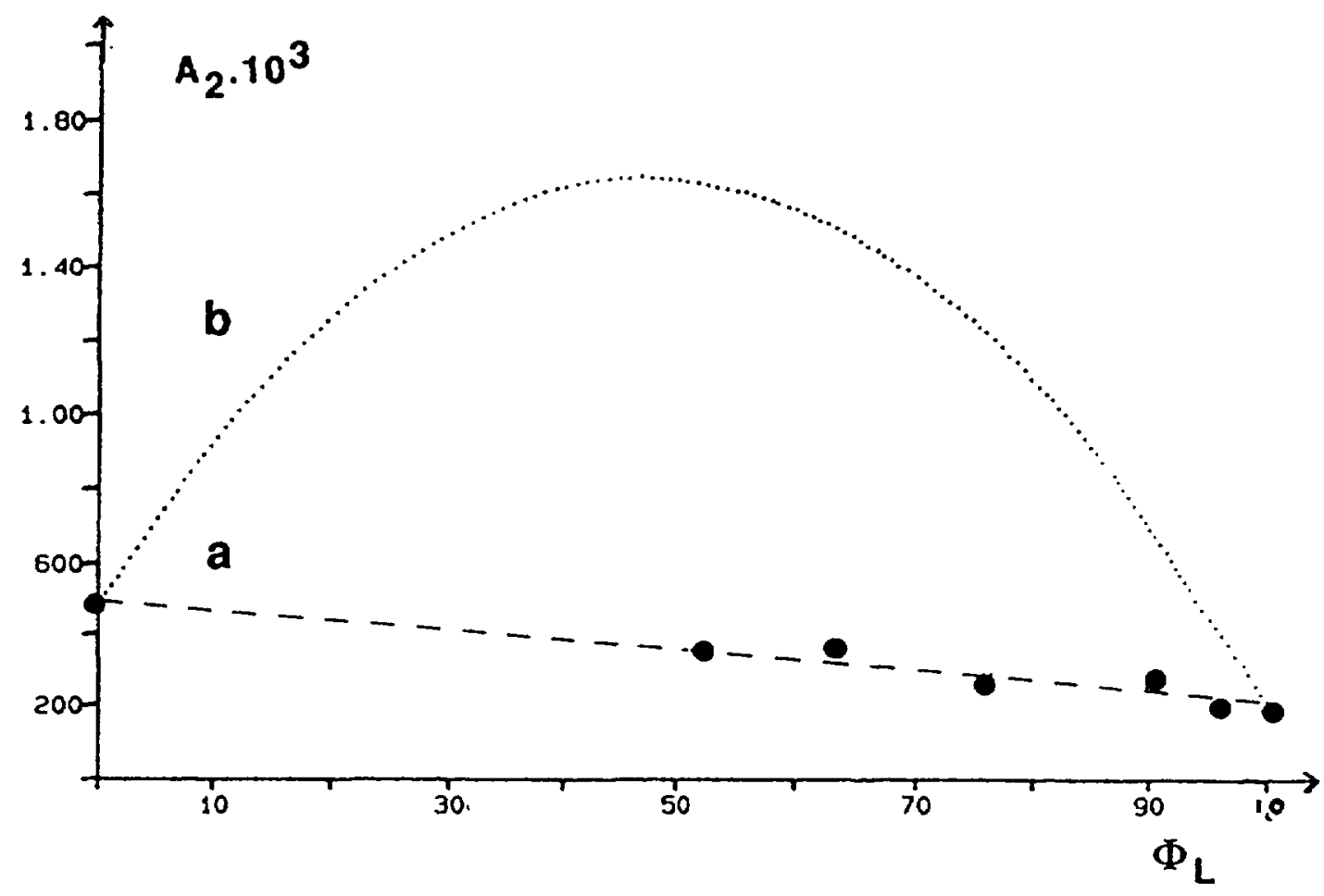

Fig. 3. - Variation of $A_{2}$ versus $\Phi_{\mathrm{L}}$ in mixture 2 (PS in toluene) : (*) experimental values obtain by light-scattering, (-.---) values predicted by the blob model, (.. ) values predicted by the hard sphere model.

Table III. - Results from light scattering on the different mixtures: mutual second virial coefficient $A_{2, \mathrm{LS}}$, mutual interpenetration function according hard-sphere $\Psi_{\mathrm{LS}}^{\mathrm{HS}}$ and Blob $\Psi_{\mathrm{LS}}^{\mathrm{B}}$ model and ratio of the mutual second virial coefficient to the second virial coefficient of the smallest chain.

\begin{tabular}{|crrrrr|}
\hline Mixture & $R_{\mathrm{L}} / R_{\mathrm{S}}$ & $A_{2, \mathrm{LS}} \times 10^{4}$ & $\Psi_{\mathrm{LS}}^{\mathrm{B}}$ & $\Psi_{\mathrm{LS}}^{\mathrm{HS}}$ & $A_{2, \mathrm{LS}} / A_{2, \mathrm{SS}}$ \\
\hline 5 & 14.7 & 6.52 & 0.27 & 0.06 & 0.88 \\
1 & 8.2 & 5.09 & 0.25 & 0.08 & 0.99 \\
2 & 6.8 & 4.36 & 0.26 & 0.04 & 0.91 \\
6 & 4.3 & 3.93 & 0.30 & 0.19 & 0.96 \\
3 & 3.4 & 4.02 & 0.13 & 0.11 & 0.96 \\
4 & 3.3 & 3.60 & 0.30 & 0.17 & 0.87 \\
7 & 2.7 & 3.20 & 0.19 & 0.18 & 1.10 \\
Theory & & & $\langle 0.19\rangle$ & $\langle 0.24\rangle$ & $\langle 0.78\rangle$ \\
\hline
\end{tabular}

$\Psi=0.24 \pm 0.04$. An equivalent result is obtained by the ratio $A_{2, \mathrm{LS}} / A_{2}$, ss with a mean value of $0.95 \pm 0.08$ which agrees qualitatively with relation (6). It is interesting to note that this ratio is systematically lower than 1 , except for mixture 7 and this is an argument to say that $\Psi_{\text {LS }}$ tends to a universal value $\Psi_{\mathrm{LS}}^{*}$, close to, but slightly lower than, $\Psi^{*}$, the asymptotic value of $\Psi$. 


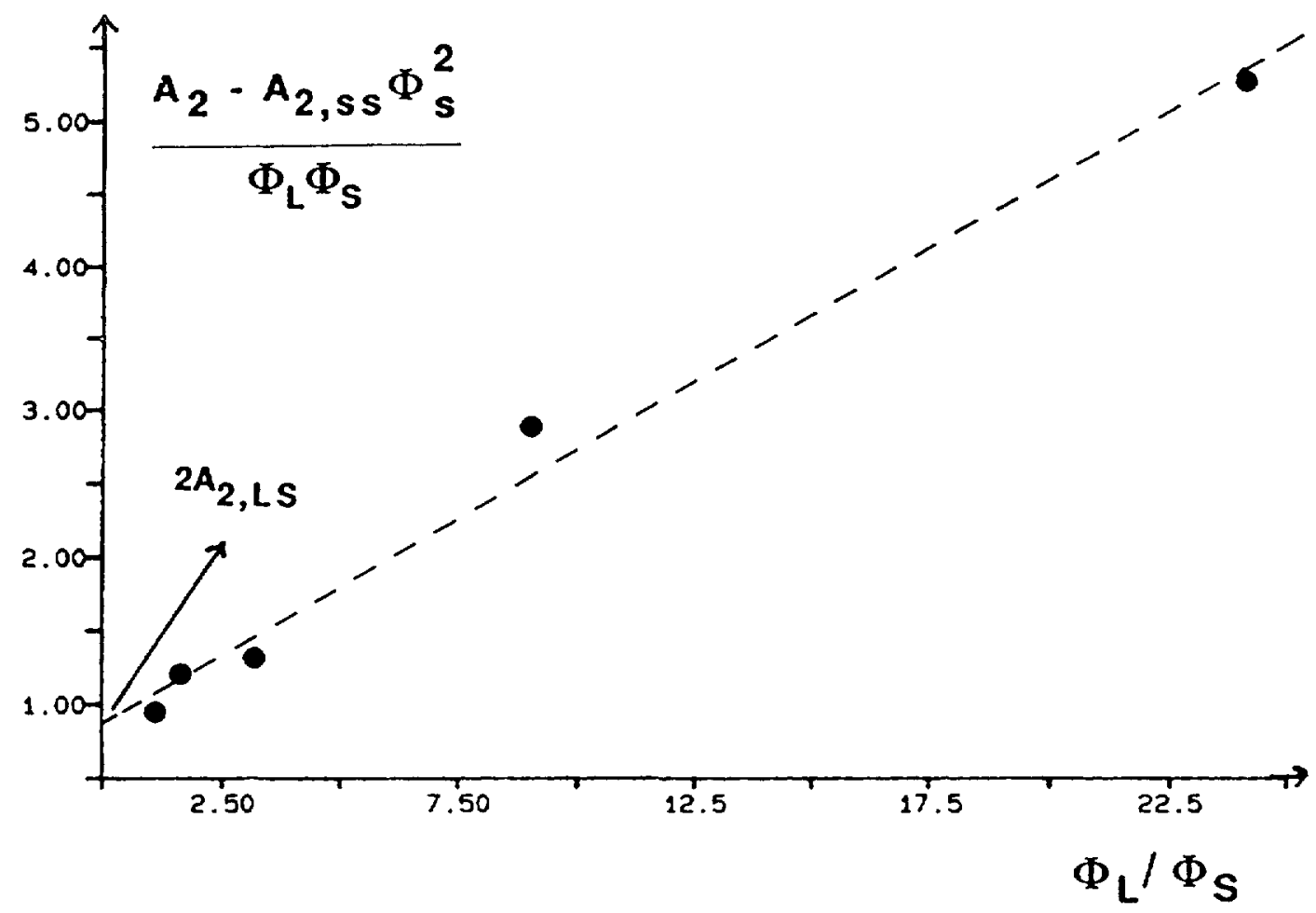

Fig. 4. - Representation of the ratio $\frac{A_{2}-A_{2, s S} \Phi_{S}^{2}}{\Phi_{L} \Phi_{S}}$ versus $\Phi_{L} / \Phi_{S}$ (see relation (12)) for the mixture 2 (PS in toluene).

\section{Conclusion.}

This experimental study shows that in the case of a mixture of polymers of very different molecular weights, the smaller chains penetrate much more the larger than a hard-sphere model would predict : we find no evidence of a maximum in the plot of $A_{2}\left(\Phi_{L}\right)$, except may be for the system with the lowest radius of gyration ratio $r$ (system 7 of Sato et al.). It must be remarked that, even in the case of polymers of large individual polydispersity, it was not necessary to take this effect into account by an assumption on the distribution. The picture suggested by the blob model seems to be more convincing according to the present results. The understanding of the polydispersity effect as a whole requires a theoretical treatment which includes the hard-sphere behavior when the chains have slightly different sizes and a blob behavior when the sizes are very different.

\section{Acknowledgments.}

We are grateful to $M$. Daoud for helpful discussions and comments on this work. 


\section{References}

[1] Des Cloizeaux J. and JANNINK G., Les Polymères en Solution : leur modélisation et leur structure (Editions de Physique, Les Ulis, 1987).

[2] DE Gennes P. G., Scaling Concepts in Polymer Physics (Cornell University Press, Ithaca, NY, 1979).

[3] Sato I., Norisuye T., Futrta H., J. Pol. Sci. B 25 (1987) 1.

[4] Mennen M. G., Smit J. A. M., Pol. Bull. 23 (1990) 67.

[5] Noda I., Kitano T., Nagasawa M., J. Polym. Sc. (Pol. Phys. Ed.) 15 (1977) 1129.

[6] Joanny J. F., Leibler L., Ball R., J. Chem. Phys. 81 (1984) 4640.

[7] OONo Y., Freed K. F., J. Phys. A 15 (1982) 1931.

[8] Witten T. A., Prentis J. J., J. Chem. Phys. 77 (1982) 4247.

[9] Yamakawa H., Modern theory of polymer solutions (Harper and Row, N. Y., 1971) p. 168.

[10] Witten T. A., Schafer L., J. Phys. A 11 (1978) 1843.

[11] DEs Clolzeaux J., J. Phys. France 42 (1981) 635. Des Cloizeaux's $g$ is related to $\Psi$ through the relation $\Psi=g\left(R^{2} / 6 R_{\mathrm{G}}^{2}\right)$ where $R$ is the end to end distance. However this ratio is very close to 1 .

[12] Lapp A., Herz J., Strazielle C., Makromol. Chem. 186 (1985) 1919 ;

LAPP A., Thèse d'état, Université de Strasbourg, France (1987).

[13] Kholkhov A. R., Makromol. Chem., Rapid Commun. 2 (1981) 633.

[14] Or «smoothed density models », see reference [2] or CASsassa E. F., Polymer 3 (1962) 625.

[15] Kirkwood J. G., Goldberg R. J., J. Chem. Phys. 18 (1950) 54.

[16] Stockmayer W. H., J. Chem. Phys. 18 (1950) 58. 